\title{
Rapid enzyme analysis of amniotic fluid phospholipids containing choline: a comparison with the lecithin to sphingomyelin ratio in prenatal assessment of fetal lung maturity
}

\author{
SH TENG, AG ANDREWS, I HORACEK \\ From the Department of Pathology, Royal Women's Hospital, Melbourne, Australia
}

SUMMARY The relation between the choline containing surfactant phospholipids lecithin and sphingomyelin in amniotic fluid and fetal lung maturity is well established. An enzymatic method that had been automated and optimised for use on a centrifugal analyser was used to measure the total choline containing phospholipids in amniotic fluid. The total time taken for this assay was 10 minutes. The results obtained from 100 patient samples, using this procedure, compared favourably with the results obtained by the thin layer chromatography procedure used to determine the lecithin to sphingomyelin ratio $(r=0.93)$. A clinical study of 60 patients showed that this assay predicted prenatal respiratory distress syndrome as well as the lecithin to sphingomyelin ratios.

The advantage of this assay over existing procedures is that it requires minimum preparation of the specimen and no extraction, is quick, and shows a high degree of precision.

The relation between the choline containing phospholipids lecithin and sphingomyelin in amniotic fluid, which is frequently expressed as the lecithin to sphingomyelin ratio, provides an effective means of evaluating fetal pulmonary maturity by measuring the increase in lecithin relative to sphingomyelin during the last trimester of pregnancy, thereby indicating to the clinician the likelihood of development of the respiratory distress syndrome in the neonatal period. ${ }^{\prime}$ Owing to the time entailed in estimating the lecithin to sphingomyelin ratio, however, and the reservations, which still exist, as to the validity of some extraction procedures, as well as the doubt expressed about some ot the thin layer chromatographic techniques currently in use for estimating the ratio, ${ }^{23}$ several enzymatic methods have been developed for measuring lecithin to sphingomyelin concentrations, or both, by spectrophotometry. ${ }^{4-6}$ These methods are only slightly less time consuming.

We report an automated enzymatic colorimetric procedure for analysing total lecithin, sphingomyelin, and lysolecithin as total choline containing

Accepted for publication 25 July 1985 phospholipids (TCCP) in amniotic fluid using a centrifugal analyser. The choline is liberated directly from amniotic fluid in accordance with the reaction sequence shown in Fig. 1 and the quinone-imine complex absorbance measured at $510 \mathrm{~nm}$.

Comparison of this method with the thin layer chromatographic procedure used routinely in this laboratory was made to determine its accuracy, specificity, and speed of analysis. A limited clinical evaluation was also carried out to determine whether this assay could predict neonatal outcome as well as the lecithin to sphingomyelin ratio.

\section{Material and methods}

\section{APPARATUS}

For the enzymatic analyses a Cobas-Bio (Roche Analytical Instruments, Nutley, New Jersey, United States) centrifugal analyser and an HP85 (Hewlett-Packard Intercontinental, Palo Alto, California, United States) computer were used. Lecithin to sphingomyelin ratios were read on a densitometer (Beckman CDS 200F) at $600 \mathrm{~nm}$.

CHEMICALS AND ENZYMES

All chemicals and enzymes were of the highest pur- 


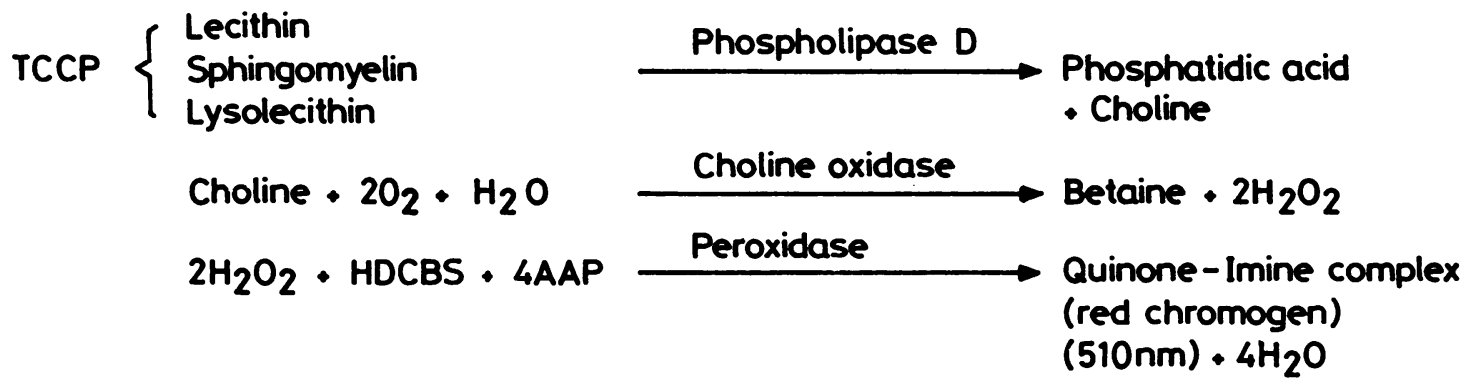

Fig. 1 Principles of the enzymatic assay for total choline containing phospholipids in amniotic fuid (TCCP). Choline is liberated from lecithin, sphingomyelin, and any lysolecithin that may be present in amniotic fuid by the enzyme phospholipase $D$ and oxidased to betaine by choline oxidase, liberating hydrogen peroxide ( 2 mol), which undergoes oxidative coupling with the chromogens 2-hydroxy-3,-5 dichlorosulfonate (HDCBS) and 4-amino antipyrene (4AAP) to form a characteristic deep red quinone-imine complex that can be measured at its optimum wavelength (510 nm) by a centrifugal analyser.

ity available from the manufacturer. Sodium 2-hydroxy-3,5 dichlorobenzene sulfonate (HDCBS) and 4 amino antipyrene (4AAP) were purchased from Aldrich. Bovine serum albumin was supplied by Commonwealth Serum Laboratories, Australia. Triton X-100 was purchased from Sigma. The enzyme sequence used for the assay was prepared from the following enzymes: phospholipase D (from Streptomyces chromofuscus; phosphatidyl choline phosphatidohydrolase, E.C.3.1.44), which was obtained from Calbiochem-Behring, Australia, and choline oxidase (from Alcaligenes; choline, oxygen 1-oxidoreductase E.C.1.1.317), together with peroxidase (from horseradish; hydrogen peroxide oxidoreductase, E.C.1.11.17) supplied by Sigma. To measure the TCCP individual phospholipid standards of $\alpha-\beta$ dipalmitoyl lecithin $(200 \mu \mathrm{mol} / \mathrm{l})$, sphingomyelin $(139 \mu \mathrm{mol} / \mathrm{l})$, and lysolecithin ( $200 \mu \mathrm{mol} / \mathrm{l})$ from Calbiochem-Behring, Australia, were prepared in $5 \mathrm{~g}$ Triton X-100/1. A composite standard of lecithin, sphingomyelin, and lysolecithin was prepared by mixing the three separate standards in the ratio $1: 1: 1 \mathrm{v} / \mathrm{v} / \mathrm{v}$. Non-choline containing phospholipids, phosphatidyl glycerol, phosphatidyl inositol, phosphatidyl ethanolamine, and phosphatidyl serine were also purchased from Calbiochem-Behring, Australia.

\section{PROCEDURES}

Specimens of amniotic fluid were obtained from women during the last trimester of pregnancy by transabdominal amniocentesis. No attempt was made to distinguish between normal patients and those with disease. The amniotic fluid was centrifuged for 10 minutes at $1500 \mathrm{~g}$ and $2^{\circ} \mathrm{C}$. The supernatant was then frozen at $-20^{\circ} \mathrm{C}$ if the analysis could not be performed immediately.

\section{AUTOMATED ENZYMATIC ASSAY}

The three enzymes were prepared in the following manner: phospholipase D (33 units/mg), choline oxidase (12.4 units $/ \mathrm{mg})$ and peroxidase ( $330 \mathrm{units} / \mathrm{mg}$ ) were diluted with $10 \mathrm{ml}$ of $0.05 \mathrm{M}$ Tris-hydrochloric acid buffer $(\mathrm{pH} \mathrm{7.8)}$ containing $0.02 \mathrm{~g}$ Triton X-100, $0.0059 \mathrm{~g}$ 4AAP, and $0.01 \mathrm{~g}$ bovine serum albumin. The working enzyme reagent was prepared by diluting nine parts of the enzyme mixture with one part of the following reagent containing $0.408 \mathrm{~g}$ HDCBS, $0.02 \mathrm{~g}$ Triton $\mathrm{X}-100$ in $10 \mathrm{ml}$ of $0.05 \mathrm{M}$ Tris-hydrochloric acid buffer $(\mathrm{pH}$ 7.8). The incubation of the reaction was carried out at $37^{\circ} \mathrm{C}$ in the Cobas-Bio centrifugal analyser. Table 1 shows all the other settings. The reaction was read at an end point, seven minutes after the initial absorbance reading at 10 seconds. The sample to reagent ratio was optimised (Table 1) to give an

- Table 1 Variables for the TCCP assay on the Cobas-Bio

\begin{tabular}{lc}
\hline Variable & Result \\
\hline Units & mmol/l \\
Calculation factor & 0 \\
Standard 1 concentration & 200 \\
Standard 2 concentration & 200 \\
Standard 3 concentration & 0 \\
Limit & 1500 \\
Temperature $\left({ }^{\circ} \mathrm{C}\right)$ & $37 \cdot 0$ \\
Type of analysis & 5 \\
Wavelength (nm) & 510 \\
Sample volume $(\mu \mathrm{l})$ & 25 \\
Diluent volume $(\mu l)$ & 40 \\
Reagent volume $(\mu \mathrm{l})$ & 150 \\
Incubation time (seconds) & 0 \\
Start reagent volume ( $\mu$ ) & 0 \\
Time of first reading (seconds) & 10.0 \\
Time interval (seconds) & 60 \\
No of readings & 7 \\
Blanking mode & 1 \\
Printout mode & 3 \\
\hline
\end{tabular}


approximate final activity of phospholipase $D$ and choline oxidase of 1.1 units and 1.4 units of activity per substrate per assay, respectively. Absorbance readings were taken at 60 second intervals and transformed to concentration values by the appropriate Cobas computer program. Each assay run contained individual lecithin, sphinogomyelin, and lysolecithin standards, as well as the composite working standard comprising all three phospholipids.

\section{ESTIMATION OF LECITHIN TO SPHINGOMYELIN}

RATIO

The lecithin to sphingomyelin ratio was estimated by the procedure described by Andrews et al, ${ }^{7}$ using methanol-chloroform extraction, cold acetone fractionation, and, finally, separation and measurement by thin layer chromatography.

\section{Results and Discussion}

\section{OPTIMISATION}

To optimise the concentration of the individual enzymes for the rapid analysis on the Cobas-Bio the composite working standard of lecithin, sphingomyelin, and lysolecithin was used. Although it has been reported that phospholipase $\mathrm{D}$ from $S$ chromofuscus hydrolyses all phospholipids that contain choline, the choline liberated from lysolecithin is generally not present in sufficient concentration in amniotic fluid to affect the value of the choline concentration due to the hydrolysis of lecithin and sphingomyelin alone, as lysolecithin is present at less than $2 \%$ of the TCCP in amniotic fluid. ${ }^{4}$

As phospholipase $D$ is the first step in the enzyme sequence (Fig. 1) it was made the rate limiting step and set at 1.1 units/assay. To ensure complete oxidation of the choline liberated by phospholipase $D$ an excess of choline oxidase was used ( 1.4 units/assay). We found, however, that a slight excess of peroxidase (1.3 units/assay), rather than a 10 fold excess as suggested by Artiss et al, ${ }^{6}$ was sufficient to allow for full colour development of the quinone-imine complex.

The effects of various buffers, salts, and metallic ions on the individual enzymes have been reported extensively, ${ }^{4-10}$ and this enabled us to select the optimum concentrations of these substances for this enzyme system. The Tris-hydrochloric acid buffer has the same concentration as that used by Artiss et al. ${ }^{6}$ We found, however, that a $\mathrm{pH}$ of 7.8 allows for the optimum activity of the individual enzymes in combination with $4 \mathrm{AAP}$ and HCDBS as a single enzyme reagent because there is little nonenzymatic coupling of the two chromogens at this $\mathrm{pH}$ and reagent concentration (molar ratio of AAP to HCDBS 1:5.9). To prevent adsorption of the enzyme to any surface $0.01 \mathrm{~g}$ of bovine serum albumin was added to $10 \mathrm{ml}$ of the enzyme reagent. Although it has been reported that Triton X-100 has a slight inhibitory effect on phospholipase activity, ${ }^{4}$ its use at very low concentrations $(0.02 \mathrm{~g} / 10 \mathrm{ml})$ prevents the precipitation of phospholipids from solution during the assay.

TEMPERATURE CONTROL

The variation of the rate of colour development with incubation temperature was assessed using an $\mathrm{AF}$ pool of intermediate TCCP concentration $(70 \mu \mathrm{mol} / \mathrm{l})$ at a fixed incubation time of seven minutes on the Cobas-Bio. The rate of colour development (change of absorbance/minute) reached a broad maximum between $35^{\circ} \mathrm{C}$ and $40^{\circ} \mathrm{C}$ On the basis that most enzyme assays performed using centrifugal analysers are performed at $37^{\circ} \mathrm{C}$ and that maximum absorbance for this assay had been attained by $37^{\circ} \mathrm{C}$, we chose $37^{\circ} \mathrm{C}$ as the incubation temperature.

\section{SPECIFICITY}

It has been reported that phospholipids not containing choline in amniotic fluid may be hydrolysed by phospholipase D from $S$ chromofuscus. ${ }^{9}$ To determine that the enzyme sequence for this assay was specific for the phospholipids containing choline known physiological concentrations of phos-? pholipids not containing choline-phosphatidyl glycerol $(10 \mu \mathrm{mol} / \mathrm{l})$, phosphatidyl ethanolamine (6 $\mu \mathrm{mol} / \mathrm{l})$, phosphatidyl serine $(15 \mu \mathrm{mol} / \mathrm{l})$, and phosphatidyl inositol ( $45 \mu \mathrm{mol} / \mathrm{l})$-were prepared in Triton X-100 in a similar manner to the phospholipids containing choline and assayed routinely with amniotic fluids for TCCP. In all cases no measurable absorbance due to the quinone-imine colour was detected by the Cobas-Bio.

\section{LINEARITY}

The linearity for each phospholipid containing choline in the presence of the two others was determined by variation of the concentration of each of the three phospholipids over a fourfold range while the concentrations of the two others were kept constant. The observed result for the variable phospholipid was compared with the expected value by the method of least squares. The linear regression lines were found to be: for lecithin, $Y=0.95 X+$ 11.4; for sphingomyelin, $Y=0.97 X+7.6$; and for lysolecithin, $\mathrm{Y}=0.88 \mathrm{X}+11 \cdot 6$. Good correlation was observed in all three cases-namely, for lecithin, $r=0.99$, for sphingomyelin, $r=0.98$, and for lysolecithin, $r=0.99$-indicating that the reaction was linear for all the phospholipids containing 
choline in the physiological and pathological ranges for amniotic fluids.

\section{PRECISION}

The precision of this assay was estimated at three different levels of choline concentration present in amniotic fluid. Selected amniotic fluids with high, medium, and low lecithin to sphingomyelin ratios $(5 \cdot 0,3 \cdot 0$, and $0 \cdot 8$, respectively) were repeatedly analysed $(n=10)$ for TCCP and then on each successive day for 10 days. The standard curve for the assay was linear to $1500 \mu \mathrm{mol}$ choline/l. The coefficient of variation for the within assay precision at the three levels was between $1.2 \%$ and $1.9 \%$ and for the between assay precision between $2.3 \%$ and $3.6 \%$.

\section{INTERFERENCE}

The presence of haem pigments is known to affect the lecithin to sphingomyelin ratio. ${ }^{11}$ To study the effect of blood contamination on the TCCP assay measured volumes of whole blood (0-20\%) were added to two amniotic fluid samples, one with a high TCCP value $(104 \mu \mathrm{mol} / \mathrm{l})$ the other with a low TCCP value ( $37 \mu \mathrm{mol} / \mathrm{l})$. The TCCP values for both amniotic fluids were increased appreciably with haemolysis; the low TCCP value was almost doubled with $2 \%$ haemolysed blood and the high value doubled with $5 \%$ haemolysis. This can produce a false mature result from an immature result when the amniotic fluid is haemolysed. Such false results, however, can be avoided by centrifuging bloodstained amniotic fluids quickly after amniocentesis to remove blood cells before haemolysis. Furthermore, most amniocenteses today are performed with the aid of ultrasound scanning, and in such cases it is most unusual to receive bloodstained specimens. Interference from bilirubin in amniotic fluid does not occur at the wavelength $(510 \mathrm{~nm})$ that the quinone-imine complex is estimated; any alteration, however, in background absorption caused either by contamination of the sample or during the reaction can be offset by monitoring the reagent blanks during the assay. The design of Cobas-Bio allows for both sample and reagent correction.

\section{APPLICATION}

A comparison (Fig. 2) was made between the Cobas-Bio method and the routine thin layer chromatographic method for the lecithin to sphingomyelin ratio $(n=100) ; 75$ of these values lay in the area that corresponded to TCCP values between 0 and $90 \mu \mathrm{mol} / \mathrm{l}$ and lecithin to sphingomyelin ratios between 0 and $2 \cdot 5: 1$. The correlation between the two methods in this clinically critical region for the prediction of lung maturity $(r=0.96$,

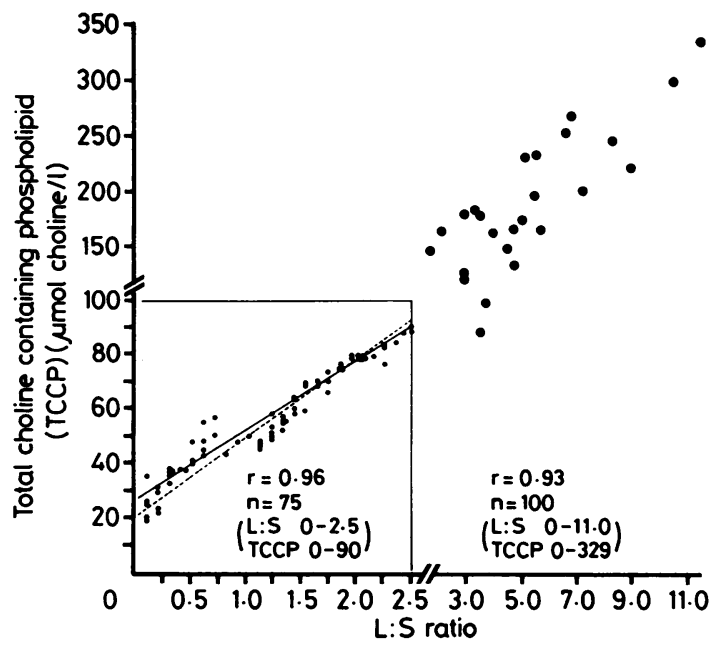

Fig. 2 Comparison of total choline containing phospholipids (TCCP) ( $\mu$ mol choline/l) with lecithin to sphingomyelin ratio in 100 amniotic fuid samples. Linear regression line (- -) is represented by $Y=29 \cdot 18 X+20 \cdot 8$. Delineated area represents $75 \%$ of total number of estimations (linear regression line (-): $Y=25 \cdot 36 X+$ 26.52).

$\mathrm{Y}=25 \cdot 36 \mathrm{X}+26 \cdot 52)$ was better than the correlation for the total number of estimations $(r=0.93, Y$ $=29 \cdot 18 \mathrm{X}+20 \cdot 8)$.

Artiss et al compared 10 amniotic fluid samples assayed by manual techniques for TCCP with the lecithin to sphingomyelin ratio, ${ }^{6}$ but because the population size was small they did not assign a cut off value for the TCCP assay at the corresponding critical value for lung maturity established for the lecithin to sphingomyelin ratio of $2 \cdot 0: 1$. In our larger study a ratio of $2 \cdot 0: 1$ corresponded to a TCCP value of $79 \mu \mathrm{mol} / 1$. Fig. 3 represents the variation of TCCP concentration with gestation; between 34 and 36 weeks a significant increase in TCCP concentration was observed (unpaired $t$ test, $p<0.001$ ), which reflects the increase in choline from the increased lecithin concentration in amniotic fluid due mainly to the increased activity of the cytidine diphosphate-choline pathway in the fetal lung as it approaches maturity. ${ }^{3}$

To compare the clinical reliability of the TCCP assay with that of the estimation of the lecithin to sphingomyelin ratio used in this laboratory the neonatal outcome of 60 pregnancies after delivery within 72 hours of the last ratio estimation were assessed. We regarded as positive those values that indicated lung maturity (lecithin to sphingomyelin ratio $\geqslant 2 \cdot 0,{ }^{7}$ TCCP concentration $\geqslant 79 \mu \mathrm{mol} / \mathrm{l}$ ) (Fig. 2 ), and as negative those values that indicated lung immaturity - that is, at risk from respiratory distress syndrome (lecithin to sphingomyelin ratio $<2 \cdot 0: 1$, 


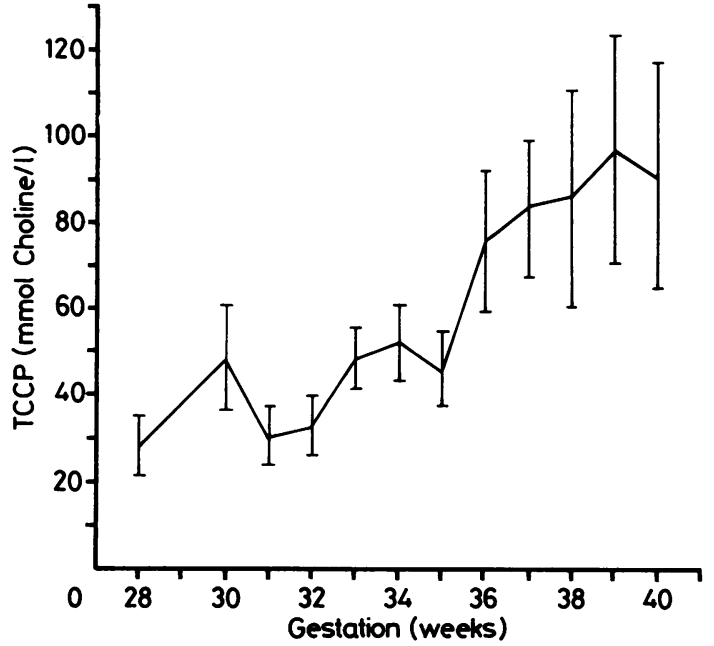

Fig. 3 Variation of total choline containing phospholipid in amniotic fuid with increasing gestational age in 100 samples. Mean ( $\pm 1 S E M)$ of from five to 15 samples are shown for each point.

TCCP $<79 \mu \mathrm{mol} / \mathrm{l})$. Using these two definitions of positive and negative, the predictability, specificity, and sensitivity of the two methods were compared (Table 2): the predictability of neonatal respiratory distress syndrome was the percentage of true negative values compared with the total number of negative values, and the predictability of no neonatal respiratory distress syndrome is the percentage of true positive values compared with the total number of positive values. The sensitivity measured the incidence of clinically defined true immature outcomes (negative test and respiratory distress syndrome), whereas specificity measured the incidence of true mature outcomes (positive test and no respiratory distress syndrome). The efficiency of each test can be expressed as a measure of true immature and true mature outcomes.

Table 2 Comparison of predictability, specificity, and sensitivity, in which sensitivity measures incidence of clinically defined true immature outcomes and specificity measures incidence of true mature outcomes

\begin{tabular}{|c|c|c|c|}
\hline $\begin{array}{l}\text { Laboratory test } \\
\text { result }\end{array}$ & $\begin{array}{l}\text { No respiratory } \\
\text { disease } \\
\text { syndrome }\end{array}$ & $\begin{array}{l}\text { Respiratory } \\
\text { disease } \\
\text { syndrome }\end{array}$ & $\begin{array}{l}\text { Total } \\
(n=60)\end{array}$ \\
\hline \multicolumn{4}{|c|}{$\begin{array}{l}\text { Predictability of neonatal respiratory disease } \\
\text { syndrome }=93 \%(93 \%)^{*} \\
\text { Predictability of no neonatal respiratory disease } \\
\text { syndrome }=96 \%(98 \%) \\
\text { Efficiency }=97 \%(98 \%) \\
\text { Sensitivity }=87 \%(93 \%) \\
\text { Specificity }=98 \%(98 \%)\end{array}$} \\
\hline
\end{tabular}

*Values in parentheses indicate lecithin to sphingomyelin ratio.
Using these definitions, the TCCP assay was marginally less efficient and less sensitive than the lecithin to sphingomyelin ratio; the specificity and predictability of neonatal outcome for both tests were similar and compared favourably with published values. ${ }^{3}$ Most patients studied $(60 \%)$ had TCCP values in the diagnostically important region 55-90 $\mu \mathrm{mol} / \mathrm{l}$ before delivery, and hence the predictability of the assays showed a corresponding bias for this region.

Measuring the lecithin to sphingomyelin ratio is labour intensive, taking two hours to complete. Several manual enzymatic techniques have also been reported, but these methods are also time consuming. In contrast, the rapid TCCP assay, which is as reliable as the lecithin to sphingomyelin ratio in predicting respiratory distress syndrome, requires minimum preparation of the specimen and produces reliable results within 10 minutes that show a high degree of precision.

We gratefully acknowledge the helpful advice of Professor JB Brown of the department of obstetrics and gynaecology, University of Melbourne, and thank Mrs K Cassidy for preparation of the manuscript.

References

' Gluck L, Kulovich MV, Borer RC, Brenner PH, Anderson GG, Spellacy WN. Diagnosis of the respiratory distress syndrome by amniocentesis. Am J Obstet Gynecol 1971;109:440-5.

${ }^{2}$ Freer DE, Statland BE. Measurement of amniotic fluid surfactant. Clin Chem 1981;27:1629-41.

${ }^{3}$ Brown LM, Duck-Chong CG. Methods of evaluating foetal lung maturity. CRC Crit Rev Clin Lab Sci 1982;16:85-159.

4 Artiss JD, Draisey TF, Thibert RJ, Taylor KE. A procedure for the direct determination of lecithin employing enzymes as reagents. Microchemistry Journal 1979; 24:239-58.

${ }^{5}$ Anaokar S, Garry PJ, Standefer JC. Enzymic assay for lecithin in amniotic fluid. Clin Chem 1978;25:103-7.

- Artiss JD, Draisey TF, Thibert RJ, Zak B, Taylor KE. The determination of lecithin and total choline-containing phospholipids in amniotic fluid employing enzymes as reagents. Microchemistry Journal 1980;25:153-68.

${ }^{7}$ McGowan WM, Artiss JD, Zak B. Enzymatic colorimetry of lecithin and sphingomyelin in aqueous solution. Clin Chem 1983;29:1513-7.

${ }^{8}$ Andrews AG, Horacek I, Betheras FR. Stabilization of bromthymol blue colour in lecithin-sphingomyelin ratio determination in amniotic fluid. J Clin Pathol 1976; 29:908-9.

- Artiss JD, McGowan MW, Standberg DR, Epstein E, Zak B. Enzymatic colorimetric determination of phosphatidyl glycerol in amniotic fluid. Clin Chem 1984;30:534-7.

10 Imamura S, Horiuti Y. Purification of Streptomyces chromofuscus phospholipase $D$ by hydrophobic affinity chromatography on palmitoyl cellulose. J Biochem 1979;85: 79-95.

" Buhi WC, Spellacy WN. Effects of blood or meconium on the determination of the amniotic fluid lecithin/sphingomyelin ratio. Am J Obstet Gynecol 1975;121:321-3.

Request for reprints to: Mr AG Andrews, Department of Pathology, Royal Women's Hospital, 132 Grattan Street, Carlton, 3053, Victoria, Australia. 